\title{
Pelatihan Pemandu Wisata Bagi Siswa Jurusan Pariwisata Di SMKN 1 Batulayar Lombok Barat
}

\author{
Sri Ariani, Tri Setianingsih*, Siti Syafiyatul Qomariyah, Bq Zuhrotun Nafisah, Ahmad \\ Hanan \\ Universitas Pendidikan Mandalika (UNDIKMA) Mataram, JI. Pemuda No. 59A, Mataram, \\ 83125 Indonesia \\ *Corresponding author email: trisetianingsih@ikipmataram.ac.id
}

\section{Diterima: Agustus 2019; Revisi: Oktober 2019; Diterbitkan: November 2019}

\begin{abstract}
Abstrak
Berkembang pariwisata di Nusa Tenggara Barat di tandai dengan pemberian anugrah destinasi wisata halal terbaik dunia, sudah menjadi kaharusan untuk menyiapkan SDM dibidang pariwisata dengan sungguh-sungguh sehingga SDM akan tetap mempertahankan anugrah tersebut. Salah satu bentuk partisifasi perguruan tinggi adalah dengan memberikan pembekalan dan pelatihan di masyarakat sekolah dan masyarakat pelaku wisata melalui kegiatan PKM. Tujuan PKM ini adalah melatih siswa jurusan pariwisata di SMK Negeri 1 Batulayar Lombok Barat untuk menjadi pemandu wisata. Kegiatan ini dilakukan di SKM Negeri 1 batu layar Metode kegiatan adalah cermah, diskusi dan praltik dengan tahapan pemberian materi, praktik, pendampingan dan evaluasi. Hasil dari kegiatan ini adalah pengetahuan dan pemahaman siswa meningkat tentang menjadi pemandu pariwisata, keterampilanketerampilan dalam memandu meningkat dilihat dari kemampuan mereka dalam menerapkan strategistrategi pemandu wisata yang profesional. Meskipun ada peningkatan sebagai calon pemandu para siswa masih kekuranga dalam berkomunikasi menggunakan bahasa inggris, sehingga kedepan perlu adanya pelatihan dan pendampingan lebih banyak, sehingga saat mereka lulus dari sekolah mereka siap menjadi pemandu yang profesional.
\end{abstract}

Kata Kunci: pelatihan; pemandu wisata

\section{Tour Guide Training for Tourism Department Students at SMKN 1 Batulayar West Lombok}

\begin{abstract}
The development of tourism in West Nusa Tenggara is marked by the awarding of the best halal tourist destination in the world, it has become a necessity to prepare HR in the tourism sector seriously so that $\mathrm{HR}$ will continue to maintain the gift. One form of university participation is to provide training and training in the school community and tourism community through PKM activities. The purpose of this PKM is to train students majoring in tourism at SMK Negeri 1 Batulayar West Lombok to become a tour guide. This activity was carried out in SKM Negeri 1 Batu Layar. The method of activity was a reflection, discussion and practice with the stages of providing material, practice, assistance and evaluation. The results of this activity are increased students' knowledge and understanding about becoming a tourism guide, and the skills in guiding are increasing in terms of their abilities to implement professional tour guide strategies. Although there are improvements as prospective guides students still lack communication in using English, so in the future there needs to be more training and mentoring, so that when they graduate from school they are ready to become professional guides.
\end{abstract}

Keywords: training; tour guide

How to Cite: Ariani, S., Setianingsih, T., Qomariyah, S., Nafisah, B., \& Hanan, A. (2019). Pelatihan Pemandu Wisata Bagi Siswa Jurusan Pariwisata Di SMKN 1 Batulayar Lombok Barat. Lumbung Inovasi: Jurnal Pengabdian kepada Masyarakat, 4(2), 61-66. doi:https://doi.org/10.36312/linov.v4i2.456 


\section{PENDAHULUAN}

Lombok yang terletak di provensi Nusa Tenggra Barat saat ini tengah menjadi icon pariwisata dunia yang ditandai dengan pemberian penghargaan di tahun 2015 yakni Lombok dinobatkan sebagai World's Best Halal Honeymoon Destination dan World's Best Halal Tourism Destination dalam ajang The World Halal Travel Summit \& Exhibition 2015. Dan di tahun 2016 NTB mendapatkan 3 (tiga) penghargaan intrnasional di ajang Halal Tourism Award 2016 di Abu Dhabi, Uni Arab Emirate (UEA). Penghargaan tersebut antara lain Novotel Lombok Resort \& Villas meraih penghargaan World's Best Halal Beach Resort. Sembalun meraih penghargaan World's Best Halal Honeymoon Destination dan www.wonderfullomboksumbawa.com meraih penghargaan World's Best Halal Tourism Website. (Radar Lombok, 2016).

Paradigma Parawisata sekarang telah berubah, dari sekedar objek rekreasi dan hiburan menjadi sebuah industri jasa yang prospektif dan multi player efek, secara terintegrasi dan bersinergi dengan sektor lainnya. Khusus bagi masyarakat, industri ini mampu memberi peluang usaha, lapangan pekerjaan yang berdampak pada peningkatan perekonomian (Christy A.R Mawene, 2019)

Lombok yang terletak di Provinsi Nusa Tenggara Barat yang terkenal dengan keindahan alamnya baik gunung, air terjun ataupun pantainya, merupakan salah satu destinasi pariwisata yang diminati oleh banyak tamu, baik tamu domestic dari berbagai daerah yang ada di Indonesia ataupun tamu dari mancanegara. Alangkah disayangkan apabila dengan banyaknya tamu yang berkunjung ke Lombok tetapi SDM yang tersedia seperti kurangnya pemandu pariwisata, kemampuan bahasa Inggris yang rendah dll. kurang memadai. Sehingga amatlah tepat apabila pemerintah mulai banyak menyelenggarakan programprogram Pendidikan yang disesuaikan dengan lapangan kerja yang dibutuhkan oleh tiap-tiap daerah.

Salah satu bentuk satuan Pendidikan formal yang menyelenggarakan Pendidikan lanjutan setelah lulus SMP/MTs sederajat selain SMU (Sekolah Menengah Umum) adalah Sekolah Menengah Kejuruan (SMK) atau Madrasah Aliyah Kejuruan (MAK), atau bentuk lain yang sederajat. Pendidikan menengah kejuruan (SMK) yang mengutamakan penyiapan siswa untuk memasuki lapangan kerja serta mengembangkan sikap profesional. Sesuai dengan bentuknya sesuai dengan Peraturan Pemerintah Nomor 29 Tahun 1990, sekolah menengah kejuruan menyelenggarakan program-program pendidikan yang disesuaikan dengan jenis-jenis lapangan kerja. Perbedaan antara sekolah umum dan SMK yakni di SMK terdapat banyak sekali Program Keahlian.

SMK Negeri 1 Batulayar merupakan salah satu sekolah menengah kejuruan di Provinsi Nusa Tenggara Barat yang terletak di kawasan Desa Batulayar Meninting Lombok Barat yang terhitung dekat dengan daerah pariwisata pantai Senggigi, yakni kurang lebih 10 $\mathrm{KM}$, juga dekat dengan Kawasan hotel dan restoran sehingga tidak salah jika sekolah ini merupakan salah satu sekolah kejuruan yang mengutamakan dunia kepariwisataan yakni meliputi Akomodasi Perhotelan, Jasa Boga, Usaha Perjalanan Wisata, dan Multimedia. Sesuai dengan visi sekolah ini yakni Menjadikan SMKN 1 Batu Layar sebagai "Sentra Inovasi Pariwisata" yang berwawasan religious, kultural, dan global". Sekolah ini memiliki 47 orang guru, 375 siswa laki-laki dan 355 siswa perempuan.

Hampir sekitar $90 \%$ siswa di SMKN 1 Batulayar berasal dari penduduk di sekitar lokasi sekolah, yakni daerah Meninting, Batulayar dan sekitarnya. Akan tetapi pada kenyaataannya masih banyak siswa yang ragu-ragu mengambil jurusan pemandu wisata karena kurangnya pemahaman siswa terhadap dunia pariwisata. Dunia wisata dianggap sebagai dunia yang banyak mudharatnya daripada manfaatnya. Banyak maksiatnya karena para siswa melihat banyaknya pakaian tamu-tamu asing yang minimalis dan terbuka. Hal lain yang menjadi perhatian tim kami yakni kurangnya pengetahuan para siswa terhadap dunia pariwisata dan juga kemampuan berbahasa Inggris pada siswa jurusan perjalanan wisata di sekolah ini. Di sampng itu tujuan dari tim kami juga ingin mempromosikan prodi fakultas Pendidikan bahasa dan seni (FPBS) yang bisa menjadi tujuan Pendidikan lanjutan bagi siswa-siswa jurusan perjalanan wisata karena ada mata kuliah pilihan dalam FPBS mengenai tour gude. 
Mengetahui beberapa kekurangan dan kelemahan pada siswa jurusan pemandu wisata yang ada di sekolah inilah yang membuat tim kami yang terdiri dari pakar dalam Speaking, Listening, grammar, Bisnis English dan Praktisi Pemandu Wisata, semangat untuk memberikan jasa pelatihan tambahan bagi para siswa kelas 3 jurusan Usaha Perjalanan Wisata yakni "Pelatihan Menjadi PemanduWisata Pada Siswa Jurusan Pariwisata di SMKN 1 Batu Layar Lombok Barat", baik dari segi pengetahuan mengenai tour guide ethics, hospitality behavior, dan percakapan bahasa Inggris untuk Pemandu perjalanan wisata agar kelak setelah lulus para siswa bisa langsung terjun ke dalam dunia kerja khususnya usaha perjalanan wisata atau tour guide dan tidak merasa canggung lagi.

Kegiatan Pelatihan ini dapat memberikan pemahaman dan pengetahuan tentang peningkatan kualitas pemandu wisata agar memiliki kualitas dan standar kompetensi yang tinggi. Oleh karena itu kami berharap kepada para peserta pelatihan untuk memanfaatkan kegiatan ini dengan baik agar bisa tampil menjadi tenaga pemandu wisata yang profesional guna peningkatan pelayanan kepada wisatawan yang berkunjung di kabupaten kita yang tercinta ini. Tujuan dari kegiatan ini adalah untuk melatih siswa jurusan pariwisata di SMKN 1 batulayar Lombok barat sebagai pemandu wisata

\section{METODE PELAKSANAAN}

\section{Tahap Requirement}

Tahap ini dimulai dengan melakukan survei terhadap mitra sehingga dapat ditemukan permasalahan apa saja yang adadi antara para siswa tentang dunia Pariwisata dan Usaha Perjalanan wisata.

Beberapa kegiatan yang dilakukan dalam tahap ini antara lain:
a. Survei lokasi mitra
b. Pembentukan tim dan tugasnya
c. Pengecekan kebutuhan media (Perangkat Keras dan Lunak)

\section{Tahap Design}

Tim membuat draft materi kegiatan yang dibutuhkan dan penentuan pembagian tugas kerja tim. Adapun materi pelatihan yang diberikan "Tour Guides Ethics", "Hospitality Behaviour" juga English for Tourism in Lombok yang ditampilkan dalam bentuk slide Power Point menggunakan LCD Projector.

\section{Tahap Implementing}

Pada tahap ini kegiatan akan dilaksanakan di SMKN 1 Batu Layar Meninting Lombok Barat yang dihadiri oleh para siswa kelas 3 jurusan SMKN 1 Batulayar Lombok Barat yang berjumlah 20 orang.

Partisipasi mitra dalam proses pelaksanaan PKM ini adalah menyediakan tempat dan memobilisasi anggota agar hadir dalam kegiatan pengabdian masyarakat ini. Hasil kegiatan yang ingin dicapai yakni meningkatnya kemampuan para siswa menjadi seorang pemandu wisata baik pemahaman tentang dunia pariwisata, tour guide ethics, hospitality behavior dan bahasa Inggris yang sering digunakan oleh tour guide di Lombok.

\section{HASIL DAN PEMBAHASAN \\ Observasi dan Interview}

Sebelum kegiatan pelatihan dilakukan terlebih dahulu kami tim PKM melakukan observasi dengan mitra sekolah dalam hal ini kepala sekolah SMKN 1 Batulayar. Hal ini bertujuan untuk mendapatkan persetujuan dan kesepakatan mengenai kapan proses pelatihan ini dapat dilaksanakan. Hasil dari observasi ini adalah disepakatinya kegiatan pelatihan menjadi pemandu wisata pada siswa jurusan pariwisata di SMKN 1 Batulayar, Lombok Barat yang berlangsung pada hari Sabtu tanggal . 27 April 2019 dibuka oleh

Selain observasi, tim PKM kami juga melakukan kegiatan interview secara langsung terhadap siswa-siswa yang dimana kegiatan ini bertujuan untuk memperoleh data dan informasi yang cukup memadai serta bagaimana pengetahuan mereka terhadap dunia pariwisata di Lombok. Dari hasil interview ternyata beberapa siswa jurusan perjalanan wisata banyak yang belum mengetahui beberapa etika tour guide, hospitality, juga cara berbicara 
bahasa Inggris. Mereka juga belum mengetahui bahwa ada jurusan bahsa Inggris di kampus IKIP Mataram yang sekarang berubah menjadi Undikma.

\section{Pelaksanaan Kegiatan}

Kegiatan pelatihan ini dilaksanakan pada hari Sabtu tepatnya pada tanggal 27 April 2019 yang diikuti oleh 20 orang siswa.. Adapun rangkaian kegiatan dimulai dari pembukaan atau sambutan dari pihak mitra yang dalam hal ini diwakilkan oleh kepala sekolah. Setelah pembukaan, salah satu anggota tim menyampaikan dan menjelaskan materi pertama yaitu mengenai "Tour Guide Ethics", dimana materi ini berisikan hal-hal yang perlu diperhatikan dalam menjadi pemandu wisata. Karena dalam melakukan tugas dan tanggung jawab sebagai pemandu wisata, seorang yang berprofesi sebagai pemandu wisata harus menguasai berbagai hal yang berhubungan dengan profesi yang ia tekuni salah satunya adalah etika yang tentunya sangat penting selain juga harus menguasai bahasa asing. Hal-hal yang harus diperhatikan tersebut adaah; 1) berpakaian sopan, 2) teknik berbicara kepada wisatawan, 3) berbicara dengan jelas, 4) memiliki arah tujuan wacana, 5) datang lebih cepat 20 menit dari waktu tour yang sudah ditetapkan, dan 6) menggunakan kalimat yang sederhana namun jelas dalam memberikan paparan mengenai suatu objek wisata.

Seorang guide dituntut untuk memberikan pelayanan yang memuaskan bagi wisatawan. Guide harus memperhatikan berbagai hal mulai dari hal-hal simple seperti datang tepat waktu hingga hal-hal yang bersifat detail seperti melakukan pengaturan perjalanan wisata. Berikut ini merupakan berbagai hal yang harus diperhatikan seorang guide untuk memberikan pelayanan prima kepada wisatawan, yaitu:

1. Datang tepat waktu

2. Memakai papan nama

3. Mengurusi bawaan si wisatawan

4. Mengurusi penginapan si wisatawan

5. Menjadi narasumber dalam perjalanan

6. Menjadi pengatur perjalanan wisata

7. Menjadi petunjuk jalan

8. Menjadi teman berbicara

9. Memberi bantuan

Setelah penjelasan mengenai "Tour Guide Ethics" berakhir, kami memberikan kesempatan kepada siswa yang mengikuti kegiatan pelatihan menjadi pemandu wisata untuk bertanya seputar materi yang belum di mengerti atau mengenai hal-hal yang berhubungan dengan dunia pemandu wisata. Beberapa peserta langsung mengajukan pertanyaan mengenai apakah selain memiliki etika dan tata karma seorang pemandu wisata harus menguasai tata bahasa asing dengan baik dan benar mengingat gambaran seorang pemandu wisata yang biasanya hanya menguasai bahasa asing secara umum. Adapaun yang bertanya mengenai berapa bahasa asing yang selayaknya harus dikuasai oleh seorang pemandu wisata, dan juga apa yang harus dilakukan ketika ingin berkarir menjadi pemandu wisata dalam artian apakah harus mengikuti pelatihan menjadi seorang pemandu wisata atau tidak. Dari beberapa pertanyaan yang diajukan oleh mereka disana dapat terlihat bahwa mereka memang sangat tertarik untuk menjadi pemandu wisata mengingat lokasi mereka yang berdekatan dengan salah satu objek wisata yang sangat banyak memiliki pengunjung tidak hanya wisatawan domestik tapi juga wisatawan luar.

Setelah pertanyaan para peserta dijawab oleh tim kami, materi kedua kemudian disampaikan kepada peserta dimana materi yang kedua mengenai "Hospitality Behaviour Guidelines". Materi kedua memiliki kesamaan dengan materi yang pertama, namun dalam materi ini lebih dijelaskan lagi hal-hal apa saja yang harus dilakukan dan dihindarai dalam memberikan pelayanan oleh seorang pemandu wisata kepada tamu wisatawan, diantaranya adalah sebagai berikut:

1. Menyapa tamu dalam jarak yang tidak terlalu berdekatan

2. Kontak mata dengan wisatwan untuk menunjukkan ketertarikan, penghormatan, dan daya tarik

3. Menebar senyum 
4. Tidak menggunakan salah satu jari ketika menunjuk sesuatu dan harus dilakukan dengan tangan terbuka atau dalam istilah bahasa Inggris disebut dengan open palm.

5. Menggunakan kedua tangan ketika menyerahkan sesuatu kepada tamu wisatawan

6. Menciptakan jarak saat berbicara. Adapun pengklasifikasian jarak ini dapat dibagi menjadi 4 klasifikasi; (a) Intimate zone berjarak antara $15 \mathrm{~cm}-46 \mathrm{~cm}$, (b) personal zone berjarak antara $46 \mathrm{~cm}-1,2 \mathrm{~m}$, (c) social zone berjarak antara 1,2 $\mathrm{m}-3,6 \mathrm{~m}$, dan (d) pulic zone berjarak lebih dari 3,6 $\mathrm{m}$.

7. Berjabat tangan

8. Berjalan tegak dengan tetap fokus ke depan

9. Tidak boleh berteriak saat berbicara dengan tamu wisatawan

10. Tidak boleh tertawa keras

11. Jauhkan gawai saat sedang melayani tamu wisatawan.

Kegiatan selanjutnya adalah pemberian materi mengenai English for Tourism in Lombok dimana selaku siswa jurusan perjalanan wisata otomatis mereka juga harus belajar bahasa Inggris yang masih menjadi bahasa Internasional. Ini akan memudahkan mereka berkomunikasi dengan tamu dari berbagai mancanegara yang berkunjung ke Lombok. Adapun beberapa bahasa Inggris Yng perlu diperhatikan adalah:

1. Greetings: tata cara menyapa tamu dengan sopan dan ramah

2. Offering: tata cara menawarkan sesuatu kepada tamu dengan baikdan sopan sehingga tamu tidak merasa tersinggung.

3. Tet acara menjelaskan destinasi wisata dengan cara yang menarik dan jelas.

4. Cara perpisahan yang baik dan sopan sehingga tamu merasa berkesan dan ingin kembali lagi ke Lombok.

Setelah sesi penjelasan tata cara Bahasa Inggris yang baik berikut cara pelafalan dan pengucapannya, pada sesi ini juga diselingi pengenalan mengenai jurusan Bahasa inggris yang ada di IKIP Mataram. Tim kami juga memberikan testimoni yang diisi oleh mahasiswa FPBS IKIP Mataram yang juga pelaku usaha perjalanan wisata /tour guide bahwa beberapa mahasiswa yang kuliah di IKIP Mataram (Undikma) bisa sambil bekerja sebagai pemandu wisata freelance yangvtidak mengikat waktu dan dapat menghasikan uang yang cukup untuk biaya mereka kuliah.

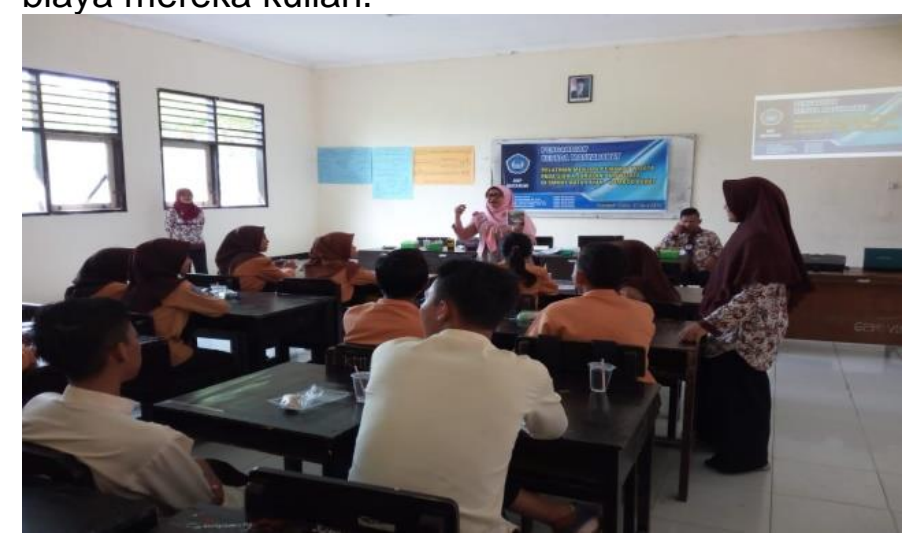

Gambar 1. Siswa Mendengarkan Penjelasan salah satu tim Speaking mengenai tata cara berbicara dengan tamu Asing.

\section{Evaluasi}

Tahap terakhir dari kegiatan PKM ini adalah melakukan evaluasi yang dimana diberikan questioner yang menanyakan apakah siswa tertarik dengan kegiatan ini dan termotivasi dengan adanya kegiatan ini.. Dari hasil evaluasi terdapat beberapa temuan, yaitu; 1) jumlah peserta sesuai dengan daftar hadir peserta dan kedatangan lebih awal dari jadwal yang sudah ditetapkan dan dari questioner yang dibagikan hampir 100\% dari mereka merasakan tertarik dan termotivasi untuk menjadi pemandu wisata yang baik, mereka juga aktif di dalam kelas pada saat sesi tanya jawab dan diskusi yang berlangsung setelah acara pelatihan yang diadakan oleh tim pengabdian kami. 2) Sangat disayangkan kurangnya kegiatan ataupun praktek lapangan yang diadakan oleh pihak sekolah yang bekerja sama dengan piha-pihak pariwisata terkait sehingga para siswa jurusan perjalanan wisata bisa lebih sering 
mempraktekan ilmu dan teori yang mereka peroleh di dalam kelas dan lebih merasa percaya diri.

\section{KESIMPULAN}

Kegiatan pelatihan ini dirasakan sangat besar manfaatnya oleh siswa, kepala sekolah berikut jajaran stafnya dan para guru. Para guru akan mempertimbangkan hasil evaluasi dengan akan megadakan kerjasama dengan pihak-pihak pariwisata terkait ssehingga siswa bisa mempraktekan ilmu dan teori yang telah diperoleh di dalam kelas. Kegiatan ini banyak memberikan pengetahuan baru bagi para siswa tentang bagaimana dunia pariwisata yang sesungguhnya. Mereka juga diajarkan bagaimana cara bersikap menghadapi tamu baik tamu domestik maupun tamu mancanegara menggunakan bahasa baik bahasa Indonesia ataupun bahasa Inggris yang baik dan dimengerti oleh para tamu lokal ataupun mancanegara.

\section{REKOMENDASI}

Pemerintah sangat mendukung perkembangan dunia pariwisata ini maka mengingat dunia pariwisata di Lombok semkin berkembang dan mengetahui bahwa pelatihan ini sangat besar manfaatnya buat para siswa di Sekolah Menengah Atas, Kejuruan dan sederajat, maka alangkah baiknya segala pihak akademisi meluangkan sedikit waktunya untuk terus meningkatkan kegiatan pengabdian yang bertujuan meningkatkan sumber daya manusia di bidang pariwisata di daerah Nusa Tenggara Barat dan Mataram pada khususnya akan dapat ditingkatkan secara terus-menerus.

Dengan banyaknya siswa yang belum paham betul mengenai peluang yang ada mengenai dunia pariwisata di Lombok, alangkah baiknya apalagi diadakan praktek kerja nyata di lokasi wisata yang banyak diminati oleh tamu baik local maupun mancanegara sehingga para siswa bisa mempraktekan ilmu yang mereka dapatkan di sekolah secara langsung. Sekolah juga perlu menjalin kerjasama dengan berbagai pihak yang bergerak di dunia pariwisata sehingga para siswa bisa menjadi siswa praktek kerja lapangan di posisi sesuai bidang jurusan yang diminati oleh siswa di sektor-sektor pariwisata yang dibutuhkan.

\section{UCAPAN TERIMA KASIH}

Terimakasih penulis sampaikan kepada semua pihak yang telah berkontribusi terhadap kesuksesan pelaksanaan kegiatan "Pelatihan Menjadi Pemandu Wisata di SMKN 1 Batulayar, Lombok Barat", baik Tim LPPM IKIP Mataram, pihak sekolah SMKN 1 Batulayar dan tim pengabdian dari FPBS IKIP Mataram.

\section{DAFTAR PUSTAKA}

Irawan, L.A. \& Suadiyatno, T. 2014. English for Lombok Tourism. Mataram: GENIUS Jurnal Administrasi Publik (JAP). Analisis Starategi Pengembangan Pariwisata. Vol. 1. No 4. Hal. 135-143

Radar Lombok (2016) Pariwisata NTB Sabet Tiga Penghargaan Internasional. https://radarlombok.co.id/pariwisata-ntb-sabet-tiga-penghargaan-internasional.html

Suwena, I Ketut \& Widyatmaja, IGN. 2017. Pengetahuan Dasar IImu Pariwisata. Denpasar: Pustaka Larasan

The World Federation of Tourist Guide Association (WFTGA). Tour Guide Ethics.

The World Federation of Tourist Guide Association (WFTGA). Hospitality Behaviour. http://www.pengertianmenurutparaahli.net/pengertian-guide-dalam-pariwisata/ Christy A.R Mawene (2019) DINAS PARIWISATA SBB ADAKAN PELATIHAN PEMANDU WISATA BUATAN. http://sbbkab.go.id/dinas-pariwisata-sbb-adakan-pelatihanpemandu-wisata-buatan/ 